\title{
Cybersickness in current-generation virtual reality head-mounted displays: systematic review and outlook
}

\author{
Polona Caserman $^{1}$ (D) Augusto Garcia-Agundez ${ }^{1} \cdot$ Alvar Gámez Zerban $^{1} \cdot$ Stefan Göbel ${ }^{1}$
}

Received: 31 July 2020 / Accepted: 2 March 2021 / Published online: 10 April 2021

(c) The Author(s) 2021

\begin{abstract}
Cybersickness (CS) is a term used to refer to symptoms, such as nausea, headache, and dizziness that users experience during or after virtual reality immersion. Initially discovered in flight simulators, commercial virtual reality (VR) head-mounted displays (HMD) of the current generation also seem to cause CS, albeit in a different manner and severity. The goal of this work is to summarize recent literature on CS with modern HMDs, to determine the specificities and profile of immersive VR-caused CS, and to provide an outlook for future research areas. A systematic review was performed on the databases IEEE Xplore, PubMed, ACM, and Scopus from 2013 to 2019 and 49 publications were selected. A summarized text states how different VR HMDs impact CS, how the nature of movement in VR HMDs contributes to CS, and how we can use biosensors to detect CS. The results of the meta-analysis show that although current-generation VR HMDs cause significantly less CS $(p<0.001)$, some symptoms remain as intense. Further results show that the nature of movement and, in particular, sensory mismatch as well as perceived motion have been the leading cause of CS. We suggest an outlook on future research, including the use of galvanic skin response to evaluate CS in combination with the golden standard (Simulator Sickness Questionnaire, SSQ) as well as an update on the subjective evaluation scores of the SSQ.
\end{abstract}

Keywords Immersive virtual reality $\cdot$ Head-mounted display $\cdot$ Cybersickness $\cdot$ Visually induced motion sickness

\section{Introduction}

Cybersickness (CS) (McCauley and Sharkey 1992), also known as virtual simulator sickness (Howarth and Costello 1997), visually induced motion sickness (Kennedy et al. 2010), or virtual reality-induced symptoms (Cobb et al. 1999) and refers to the negative effects users experience during or after immersion into virtual reality (VR) (Kim et al. 2015; Stanney et al. 2003; Merhi et al. 2007). CS is similar to motion sickness and is commonly associated with vection (Hettinger and Riccio 1992; LaViola 2000; James Smart

Polona Caserman

Polona.Caserman@kom.tu-darmstadt.de

Augusto Garcia-Agundez

Augusto.Garcia-Agundez@kom.tu-darmstadt.de

Alvar Gámez Zerban

Alvar.Zerban@kom.tu-darmstadt.de

Stefan Göbel

Stefan.Gobel@kom.tu-darmstadt.de

1 Multimedia Communications Lab, Technical University of Darmstadt, 64283 Darmstadt, Germany et al. 2002), but the exact relation between both is unknown. Recent studies suggest that vection is a necessary, but not sufficient, prerequisite for CS (Keshavarz et al. 2015; Kennedy and Fowlkes 1992). CS is nevertheless not restricted to VR and also occurs in other visual display systems, such as large screens, curved screens, and CAVEs (Rebenitsch and Owen 2016). However, in this systematic review, we focus only on CS in current-generation immersive VR HMDs, such as Oculus Rift and HTC Vive.

Empirical evidence shows that $60-95 \%$ of participants experience some level of CS during exposure to a virtual environment, whereas $6-12.9 \%$ of the participants prematurely end their exposure (Stanney et al. 2003; Arns and Cerney 2005; Roberts and Gallimore 2005; Regan 1995a, b; Kim et al. 2005). CS usually appears approximately 10-15 min after immersion (DiZio and Lackner 1997, 2000; Lampton et al. 1994), although cases have been reported with less time (So and Lo 1999). Once the user leaves the VR environment, symptoms usually disappear in around 15 min (DiZio and Lackner 1997, 2000), but reimmersion causes them to reappear abruptly and severely (DiZio and Lackner 2000). The duration of this susceptibility is unclear 
(Viirre and Ellisman 2003) and some studies suggest that aftereffects can also persist for hours (Johnson 2005).

Numerous potential solutions to CS have been discussed, e.g., a virtual nose (Whittinghill et al. 2015; Wienrich et al. 2018) or motion sickness medication (Chen et al. 2015). Many previous studies suggest different methods to reduce the discrepancy between virtual and real movements, such as restricting movement to instantaneous locomotion (Christou and Aristidou 2017), manipulating the limited physical VR space with acoustic redirected walking (Nogalski and Fohl 2016), or extrapolating and filtering head movements (Garcia-Agundez et al. 2017). Including environmentally meaningful features such as sound and vibration when operating a virtual vehicle (Sawada et al. 2020) or snapping the viewpoint in sections of significant movement (Farmani and Teather 2018) have also been mentioned. However, user adaptation is widely regarded as the best option to address CS at the moment (Johnson 2005; Golding and Gresty 2015).

The etiology of CS is undetermined and coexists with the possible causes of common motion sickness. The three most common theories are: (1) a sensory conflict theory that is based on a discrepancy between the visual, vestibular, and proprioceptive senses, as well as on expectation and past experience (Reason and Brand 1975), (2) the postural instability theory that describes a physiological response to the inability to maintain bodily postural control (Riccio and Stoffregen 1991), and/or (3) the eye movement theory (Ebenholtz et al. 1994). However, even though several studies support these theories, other studies present competing hypotheses for the cause of motion sickness. For example, Bos (2011) reviewed these findings and found negative correlations between postural instability and CS. Similarly, Lubeck et al. (2015) conclude that postural sway is not necessarily increased by visual motion. Another possible cause is the vergence-accommodation conflict, or the mismatch between the actual and eye focusing distance of a 3D object, as discussed by Kramida (2016). Further research suggests a subjective vertical mismatch theory: when subjective vertical cannot be determined, this will cause motion sickness in general (Bles et al. 1998) and CS in particular (Bos et al. 2008). Additional studies also mention the poison theory as a possible cause for CS (Treisman 1977); however, as already argued by LaViola (2000), this theory is substantially different from the other mentioned before and difficult to verify.

There exist various questionnaires to assess CS, e.g., Motion Sickness Susceptibility Questionnaire (Golding 1998) or Fast Motion Sickness Scale (Keshavarz and Hecht 2011). However, the golden standard is the Simulator Sickness Questionnaire (SSQ) (Kennedy et al. 1993). Studies have been made explicitly on its suitability for VR (Bruck and Watters 2011), considering the differences between CS and simulator sickness (Stanney et al. 1997). In the SSQ, the possible symptoms of CS are evaluated on a scale from zero (none) to three (severe) and then grouped into three blocks: nausea, oculomotor, and disorientation. Finally, a total SSQ score is derived from these three blocks and the simulation is then categorized depending on its score: negligible (SSQ lower than 5), minimal (5-10), significant (10-15), concerning (15-20), and bad simulator (20 or higher) (Stanney et al. 1997). Disorientation symptoms are predominant in CS (Stanney et al. 2003; Kim et al. 2005; Lampton et al. 1994; So and Lo 1999; Lo and So 2001), whereas oculomotor ones are typical of simulators (Stanney et al. 1997) and nausea, as well as emesis, are predominant in motion sickness. Moreover, the incidence of CS has been reported to be 2.5-3 times higher than simulator sickness (Kennedy and Fowlkes 1992; Roberts and Gallimore 2005; Stanney et al. 1997).

Although the amount of research into CS is, as shown, quite extensive, user complaints are still fairly common (Rangelova et al. 2020), so an issue in current HMDs still remains. Current-generation HMD devices, such as the Oculus Rift, have already proven to cause CS (Kim et al. 2015; Garcia-Agundez et al. 2017; Gavgani et al. 2017). Many previous publications explored different factors affecting CS, e.g., individual (age, gender, illness, posture), device (lag, flicker, calibration, ergonomics), and task factors (control, duration) (LaViola 2000; Davis et al. 2014). Similarly, Chang et al. (2020) recently surveyed the causes of CS and identified three major factors (hardware, content, and human factors). Additionally, Rebenitsch and Owen (2016) provide an excellent review on CS. However, these publications usually focus on determining the factors affecting CS and do not consider different VR HMDs, such as HTC Vive.

Hence, in contrast to related work, we conducted a metaanalysis, comparing different HMDs (e.g., Oculus Rift vs. HTC Vive) and stimuli (matched vs. mismatched). The goal of this systematic review is to provide further insight of CS in current-generation immersive VR HMD from three perspectives. Firstly, we aim to determine whether there are significant differences in the intensity and patterns of CS, measured by the SSQ among different VR HMDs (see Sect. 3.1). Secondly, we explore the nature of movement that causes sensory mismatch (see Sect. 3.2). Finally, we determine how biosignals may detect CS (see Sect. 3.3). This may help researchers to draw more definite conclusions into whether these factors do have a significant impact on CS.

\section{Methods}

In order to conduct the study, we performed a systematic search with the following keywords: virtual reality AND (cybersickness OR simulator sickness OR motion sickness) AND (application OR game), published since January 1, 


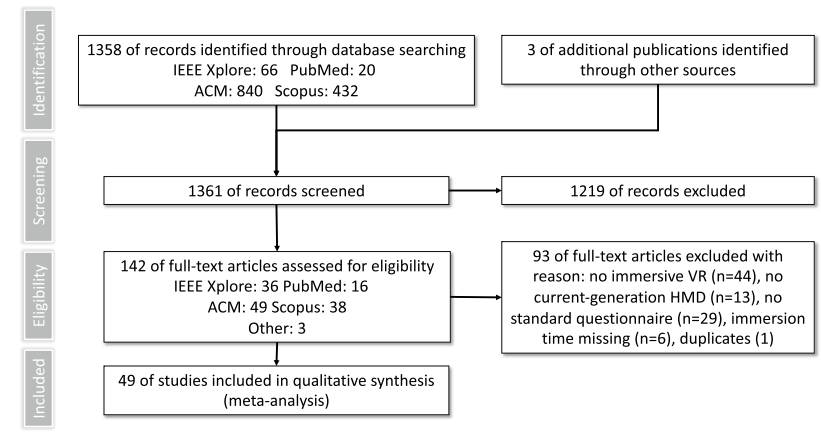

Fig. 1 PRISMA (Moher et al. 2009) flowchart of study selection

2013 (release of the first current-generation HMD, Oculus Rift DK $1^{1}$ ). The search was performed on July 17th, 2019. Inclusion criteria were: (1) the immersive VR application uses a current-generation HMD, (2) the study measures CS with a standard questionnaire, and (3) the study reports some degree of CS among its participants. Exclusion criteria were: (1) non-HMD-based VR applications (e.g., large screens or CAVEs), (2) the study does not specify the immersion time, (3) reviews, (4) keynotes, and (5) books.

Figure 1 shows an overview of the study selection, as proposed by Moher et al. (2009). In total, we identified 1358 articles through database searching and three further articles through other sources that meet our requirements. After the preliminary screening (i.e., screening of title and abstract), we excluded 1219 records because they did not rely on an immersive VR system (thus, not using a HMD). Afterward, we applied eligibility criteria, again excluding further 93 articles. Finally, we could reduce our corpus to a total of 49 articles.

For the analysis, we extracted important information, e.g., number of users, total immersion time, version of HMD used in experiments, type of application, condition (sitting or standing), and locomotion technique. Then we grouped the publications based on the HMD version and stimuli. We furthermore obtained for each publication total SSQ score (mean and standard deviation). All resulting data for the studies can be consulted in Table 1. Data refers exclusively to post-immersion, non-normalized SSQ scores since normalization was not always performed.

We furthermore conducted a meta-analysis using the "meta" package in R statistical software (Schwarzer et al. 2015). We calculate the overall effect (mean differences), its confidence interval, and p-values to compare SSQ values for different types of VR HMDs (e.g., Oculus Rift vs. HTC Vive) and different stimuli (matched vs. mismatched

\footnotetext{
1 https://www.kickstarter.com/projects/1523379957/oculus-rift-stepinto-the-game/posts/440293, last visited on October 25th, 2019.
}

stimuli). Therefore we filtered the research corpus again and excluded articles that (1) did not employ the SSQ or (2) did not provide explicit SSQ data. The results of the metaanalysis of 32 leftover articles are detailed in Tables 2 and 3.

\section{Results}

\subsection{On the differences in CS patterns with different HMDs}

In order to determine if there are differences in the CS patterns based on different HMDs, we obtained the total SSQ score and subscores (nausea, oculomotor, and disorientation scores) if available. The results of this analysis are presented in Fig. 2.

Several observations can be extracted from this data. The HTC Vive shows clearly the best SSQ values in total score as well as in nausea and disorientation subscores. Regarding oculomotor scores, Oculus Rift DK1 and HTC Vive have similar results. However, this may be due to the limited sample size since there are only four available subscores for DK1 (in contrast, for Vive, nine studies reported subscores, including nausea, oculomotor, and disorientation). As detailed in Table 3, there are also significant differences between the HTC Vive and the Oculus Rift DK1 as well as DK2 for all stimuli $(p<0.0001)$. Unfortunately, there are not enough studies or information to elicit a comparison between the Oculus Rift CV1 and HTC Vive. In any case, future studies would likely increase statistical power.

Considering the differences between the Oculus Rift DK1 and the DK2 are not significant ( $p=0.4764)$, we suspect that changes in resolutions and refresh rates have had only a marginal impact on CS when compared to changing the means of locomotion and environment interaction, which is the essential difference between the presented HMDs (see also Sect. 3.2). In fact, we observed higher scores in the Oculus Rift DK2 in comparison to the DK1 (see Fig. 2). However, as already mentioned before, this may be due to the limited sample size. Nevertheless, as can be seen in Table 1, Oculus Rift DK1 causes a higher withdrawal rate (24.50\%) compared to DK2 (9.60\%). Since the production of Oculus Rift DK1 and DK2 has been stopped, it is unlikely that more results will arise in the future.

\subsection{On nature of movement}

\subsubsection{Sensory mismatch}

Many studies have drawn attention to the fact that mismatched stimuli cause subjects to experience CS. In particular, CS occurs when the users perceive self-movement in the virtual environment while actually remaining 


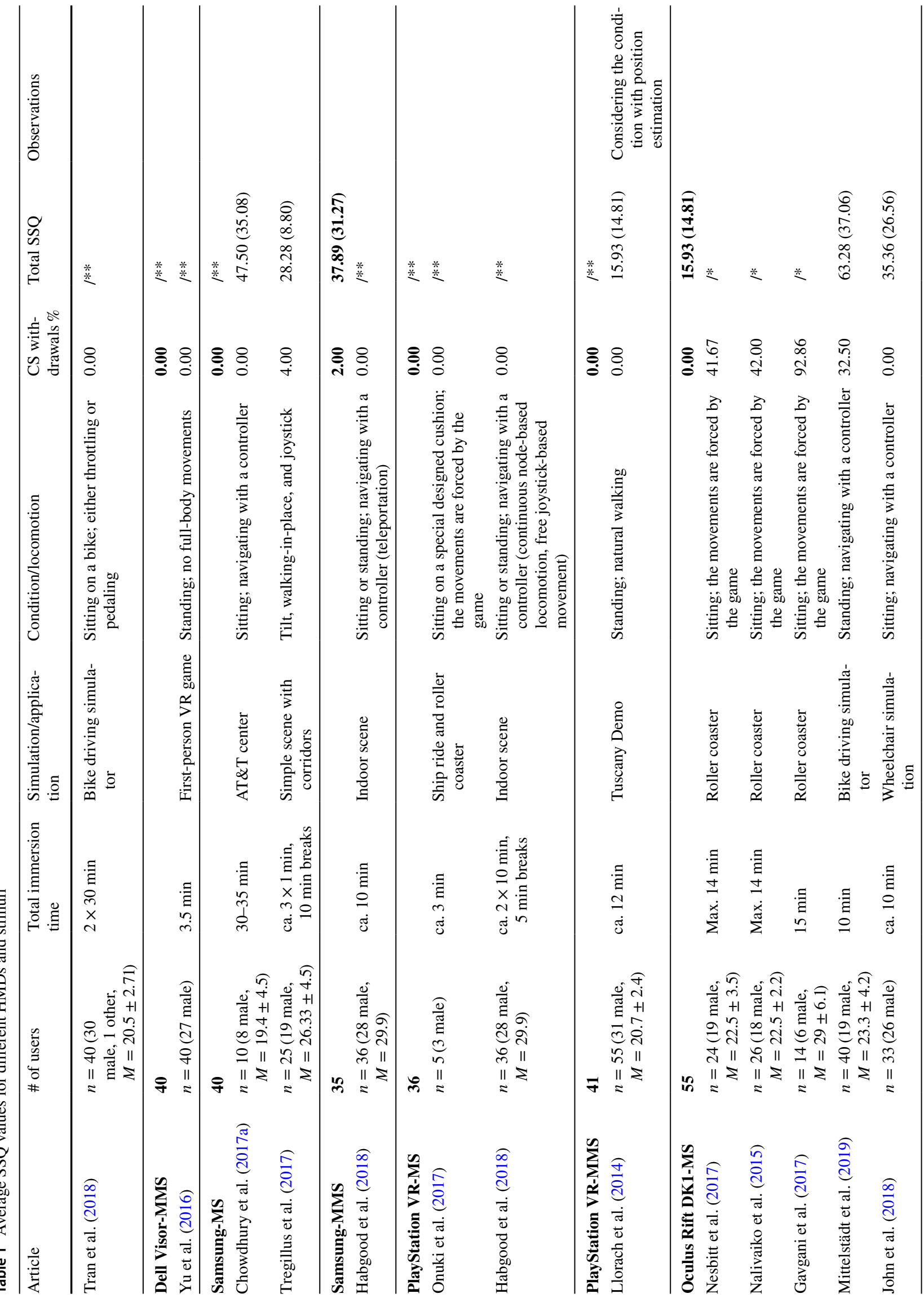




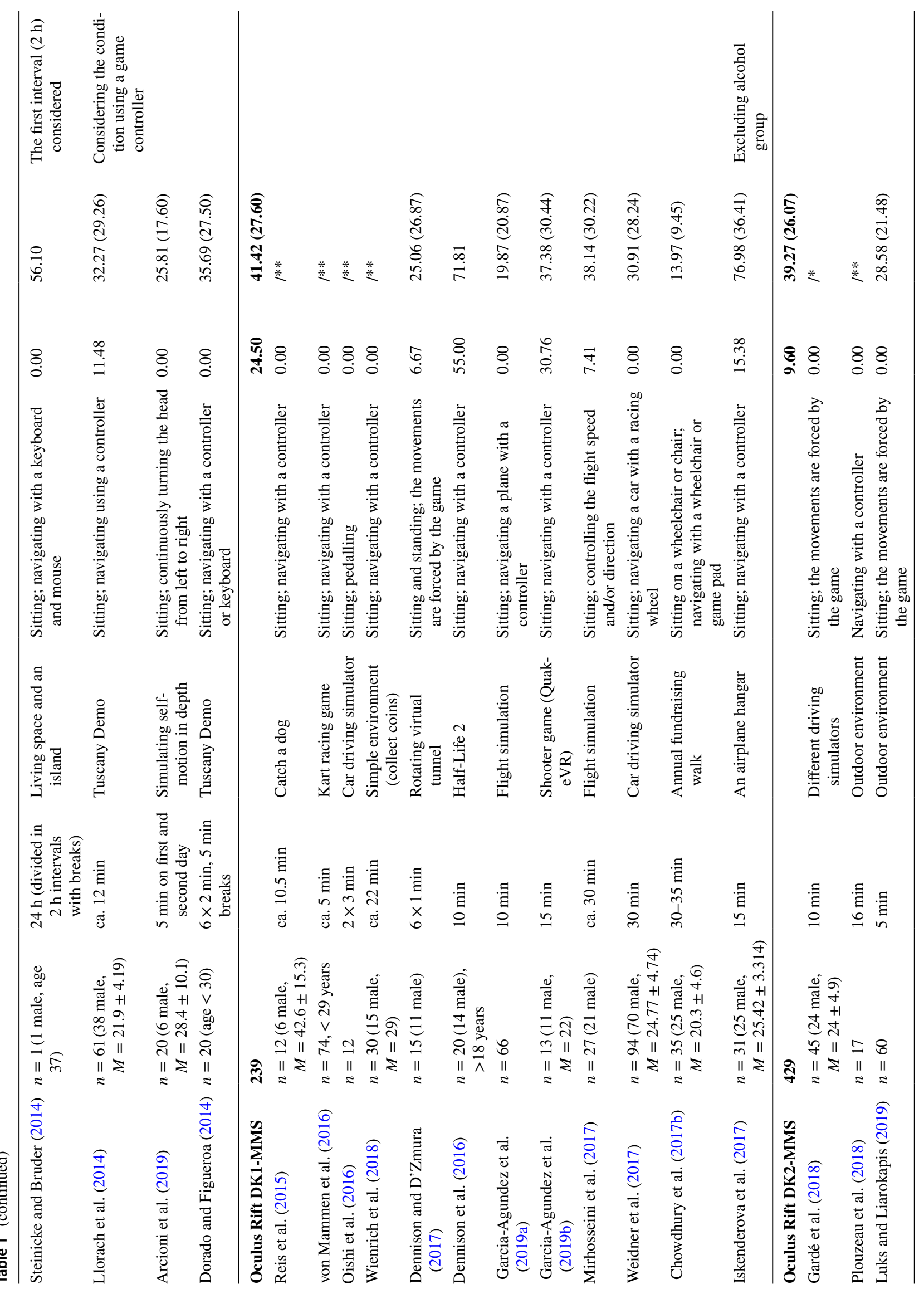




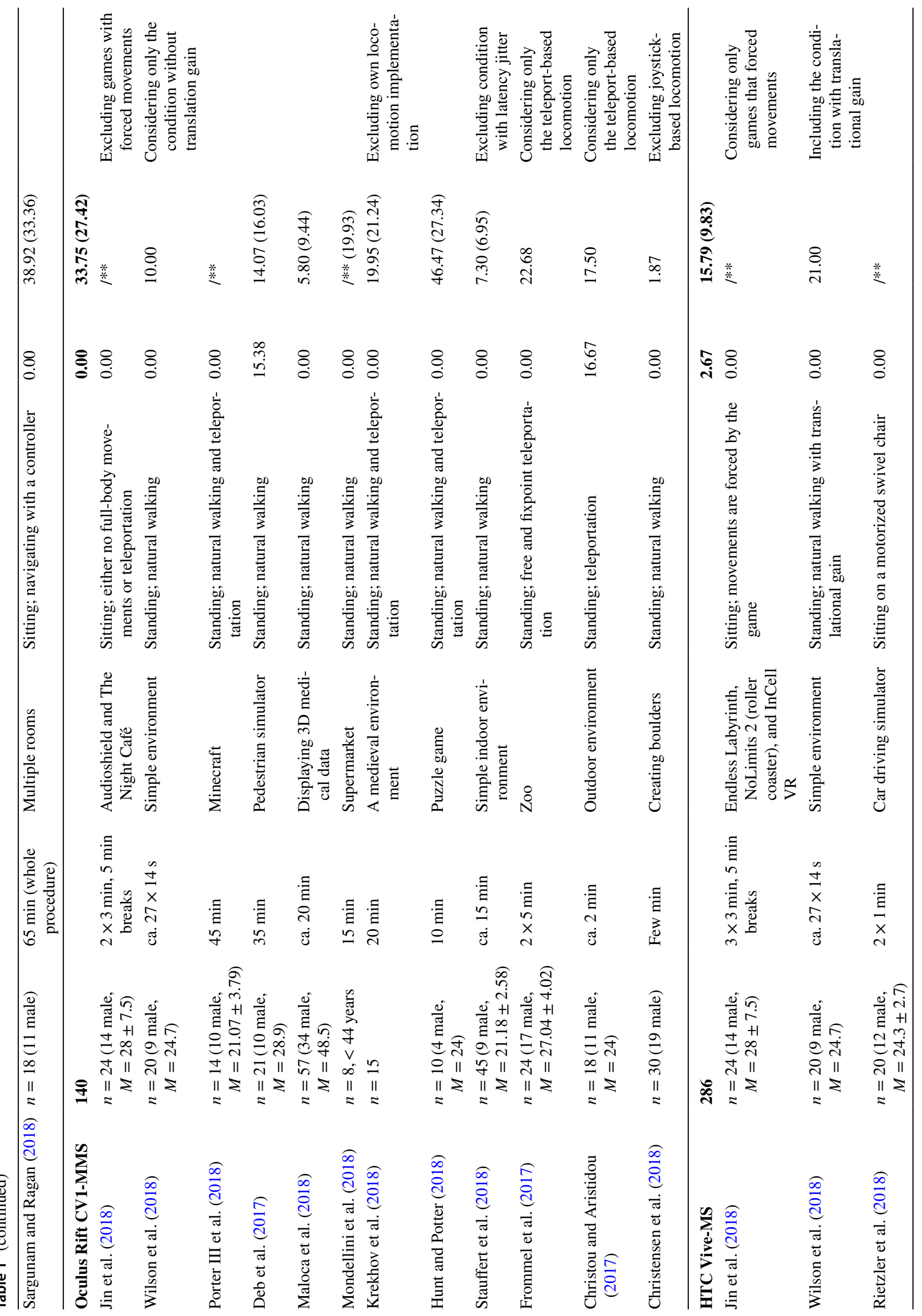




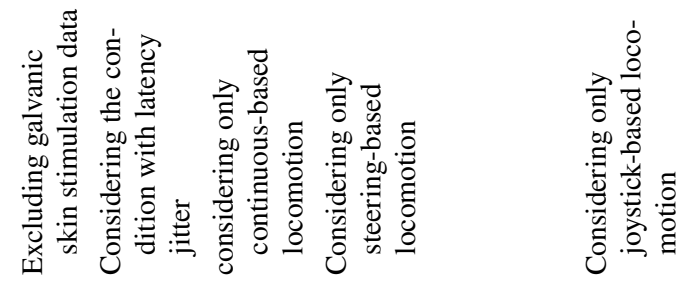

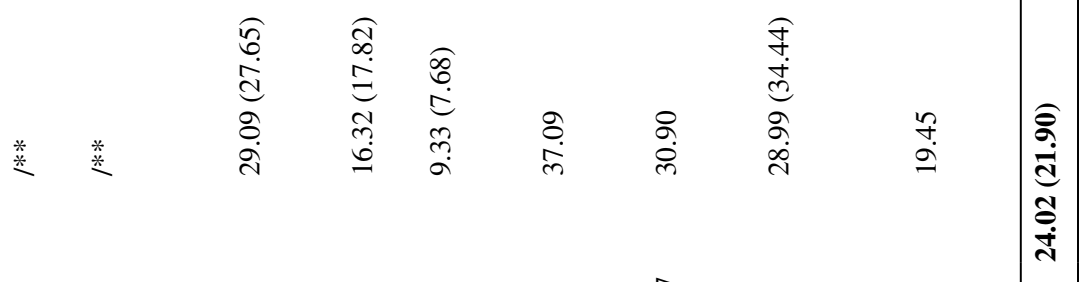

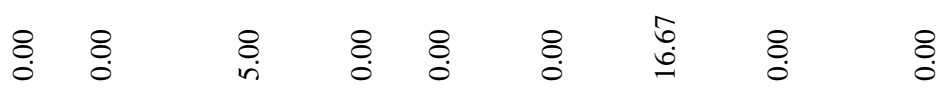

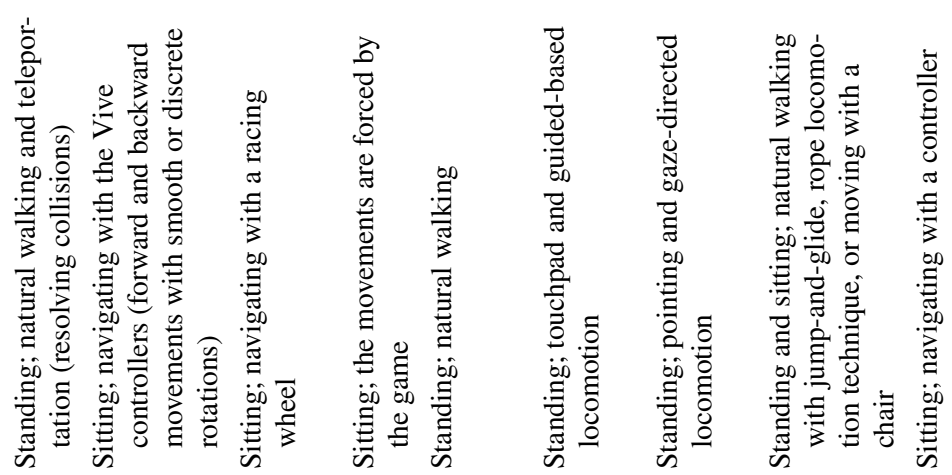

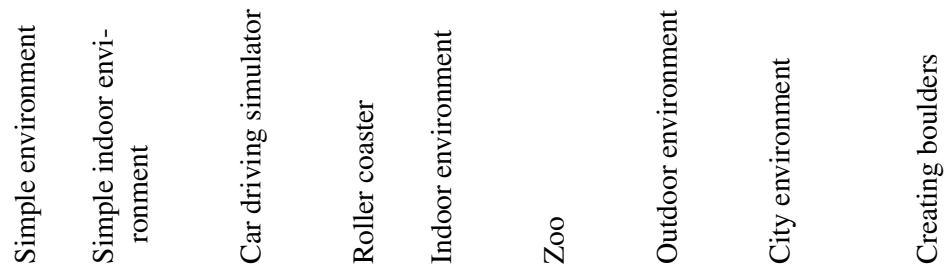

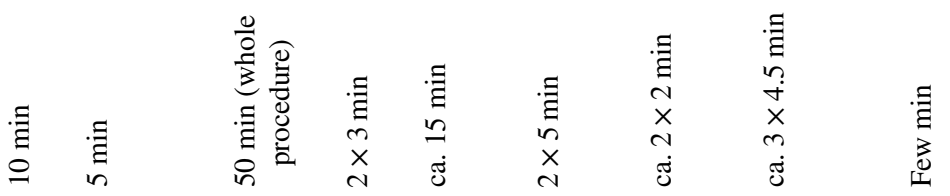

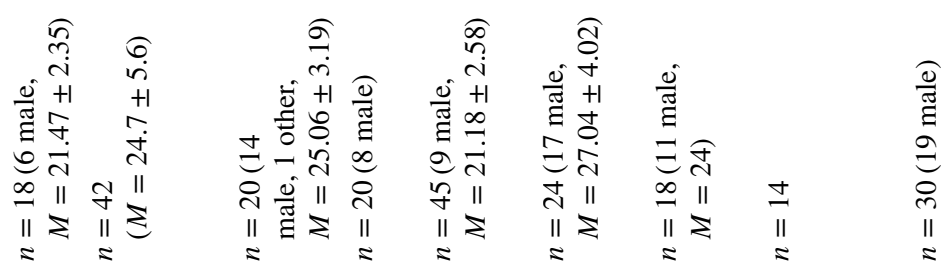

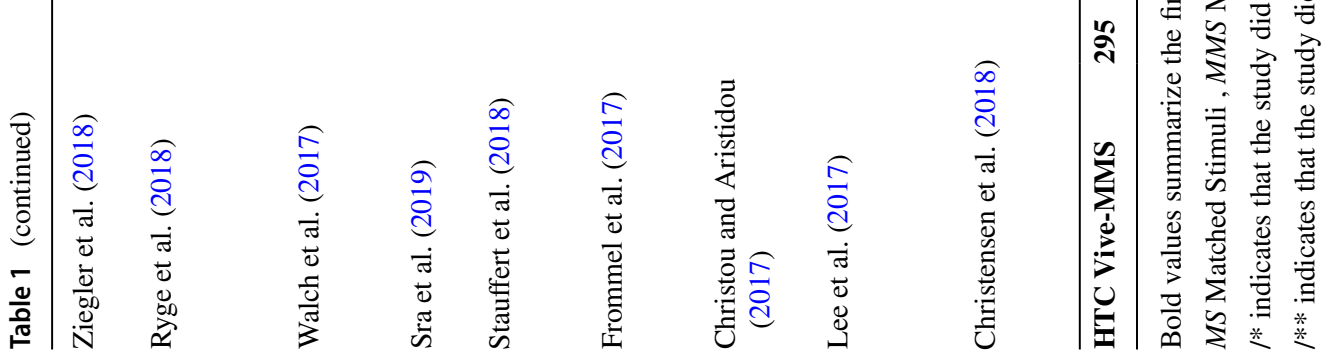


stationary, e.g., different kinds of driving or flying simulators (see Sect. 3.2.2) and different locomotion techniques (see Sect. 3.2.3).

Therefore, to further investigate the effect of sensory mismatch, we conducted a meta-analysis on different VR HMDs and different stimuli. The data in Table 2 and Fig. 3 show lower SSQ scores for virtual environments with matched stimuli (average SSQ values of 12.78) compared to virtual environments with mismatched stimuli (average SSQ values of 31.84 ). Furthermore, on average, $7.11 \%$ of the subjects dropped out when perceived and real motions do not match (see Table 1). In contrast, studies with matched stimuli show lower withdrawal rates (on average, $3.21 \%$ of the subjects dropped). These results show that the SSQ scores and the withdrawal rate are higher for mismatched stimuli. Moreover, the meta-analysis results in Table 3 show that total SSQ scores between mismatched and matched stimuli are significantly different $(p<0.0001)$.

We furthermore analyzed the SSQ scores of matched and mismatched stimuli depending on different HMDs. As detailed in Table 3, there is a significant difference between matched and mismatched scores for Oculus Rift DK1 $(p<0.0001)$ and HTC Vive $(p=0.0169)$. In fact, we found a significant difference for HTC Vive compared to other HMDs for mismatched stimuli; however, not for matched stimuli. For example, we found a significant difference between mismatched stimuli between HTC Vive and Oculus Rift DK1 $(p<0.0001)$ as well as Vive and DK2 $(p<0.0001)$; however, not between matched stimuli for Vive and DK1 $(p=0.0944)$. Unfortunately, we could not compare HTC Vive and Oculus Rift DK2 because our analysis does not include any study reporting SSQ values for matched stimuli for DK2. Nevertheless, because there is a significant difference between matched and mismatched stimuli independently of the HMD, we can assume that the mismatched stimuli are one of the main causes of CS.

Additionally, a too high latency can cause a mismatch between the perceived and real motions. Thus, the latency of a HMD can contribute to CS, especially when the users can perceive a latency lag between the head movements and the corresponding visual feedback on the HMD. Latency jitter seems to significantly affect CS (Stauffert et al. 2018). Delays above $40 \mathrm{~ms}$ already evoke CS (DiZio and Lackner 2000), although significant CS symptoms appear upwards from $75 \mathrm{~ms}$ (Caserman et al. 2019). Many researchers suggest keeping the latency below $20 \mathrm{~ms}$; however, the latency does not appear to be the main cause for CS and a significant decrease in the overall system's latency will not abolish CS (Fuchs 2017).
Table 2 SSQ scores regarding different HMDs and stimuli

\begin{tabular}{lll}
\hline & \# of users & M (SD) \\
\hline MMS, all devices & 667 & $31.84(30.29)$ \\
MMS, Oculus Rift DK1 & 174 & $39.63(32.09)$ \\
MMS, Oculus Rift DK2 & 281 & $31.97(31.41)$ \\
MMS, Oculus Rift DK1+DK2 & 455 & $34.9(31.86)$ \\
MMS, HTC Vive & 99 & $17.51(21.7)$ \\
MS, all devices & 203 & $12.78(16.35)$ \\
MS, Oculus Rift DK1 & 55 & $15.93(14.81)$ \\
MS, Oculus Rift DK2 & 0 & $/$ \\
MS, Oculus Rift DK1+DK2 & 55 & $15.93(14.81)$ \\
MS, HTC Vive & 148 & $11.61(16.78)$ \\
DK1, all stimuli & 229 & $33.94(30.6)$ \\
DK2, all stimuli & 281 & $31.97(31.41)$ \\
Oculus Rift DK1+DK2, all stimuli & 510 & $32.86(31.04)$ \\
Vive, all stimuli & 247 & $13.98(19.08)$ \\
\hline
\end{tabular}

We excluded publications with no dispersion (SD) data

/ that no studies reported SSQ values

$M S$ matched stimuli, $M M S$ mismatched stimuli, $M$ mean, $S D$ standard deviation

\subsubsection{Perceived motion in VR simulators}

Some studies explicitly investigated the severity of CS in VR simulators, e.g., roller coasters or other driving and flying simulators. Roller coasters usually cause participants to terminate the ride prematurely due to nausea. For example, researchers report a withdrawal rate of up to $92.86 \%$ (Nesbitt et al. 2017; Nalivaiko et al. 2015; Gavgani et al. 2017). These kinds of driving or flying simulators provoke CS because subjects usually sit in a stationary chair while exposed to linear and angular accelerations. Furthermore, several studies show that SSQ scores are generally higher in VR-HMD conditions compared to non-VR conditions. For example, Walch et al. (2017) studied the intensity of CS while the participants either drove a car visible on the flat screen or via a HMD. In this study, the participants reported higher CS symptoms scores in VR-HMD setup (SSQ scores of 29.09) compared to the screen setup (SSQ scores of 16.41). Weidner et al. (2017) have expressed a similar view. The researchers report that in the VR-HMD condition, the participants reported significantly higher CS symptoms (SSQ scores of 30.91) than in the stereoscopic 3D condition (SSQ scores of 13.49). As discussed by Kramida (2016), the vergence-accommodation conflict could be an explanation for this difference. 


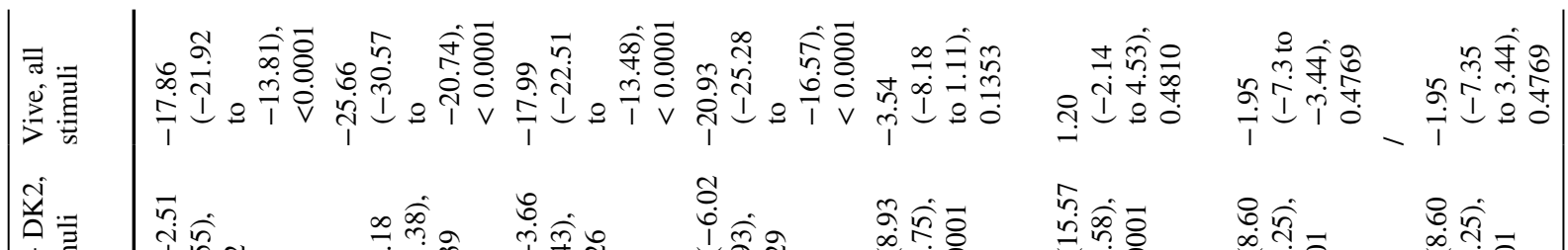

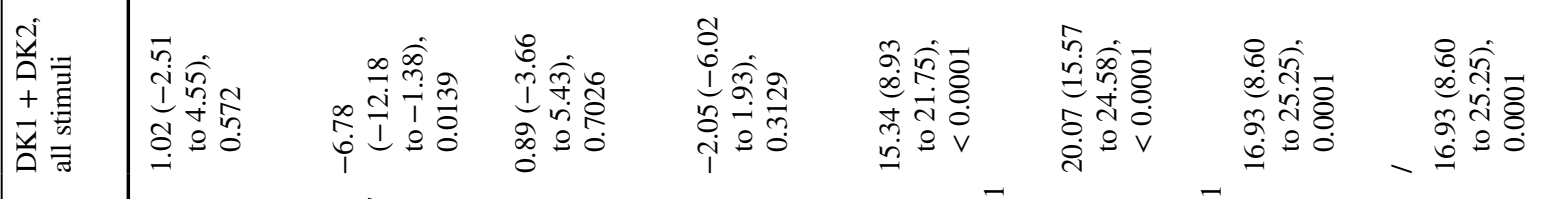

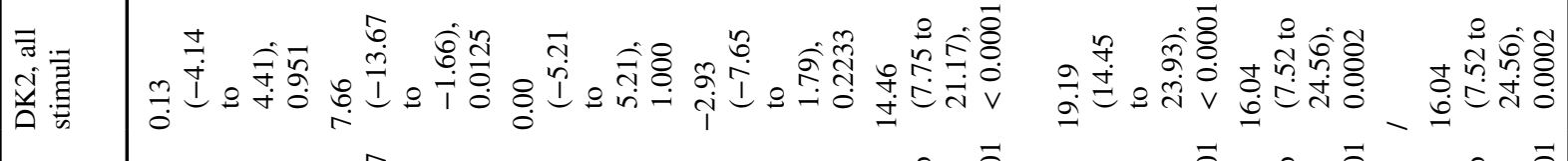

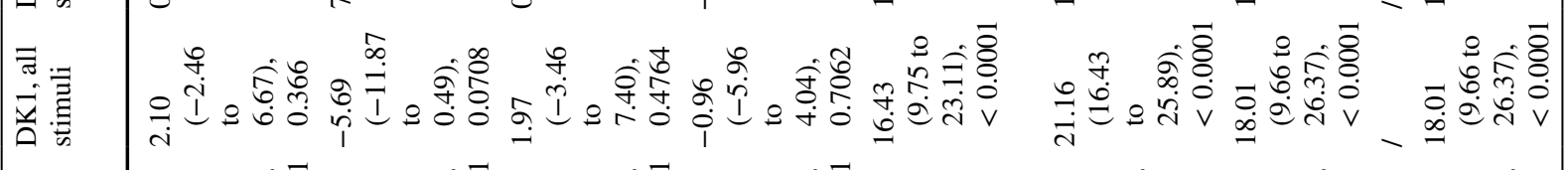

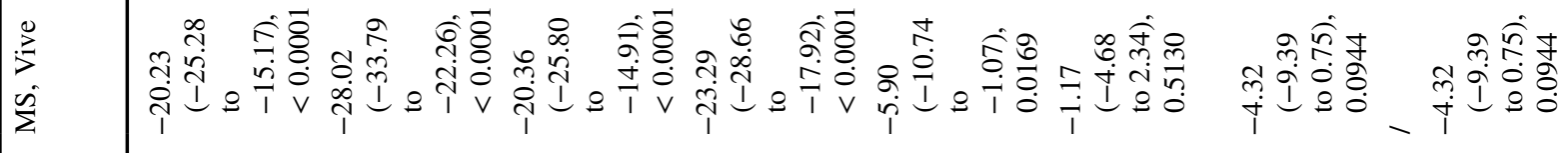

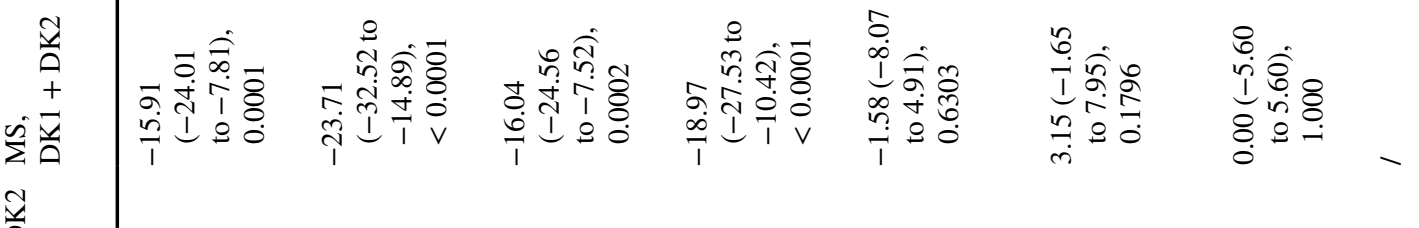

$$
\begin{aligned}
& \text { ำ } \\
& \text { 站 }
\end{aligned}
$$

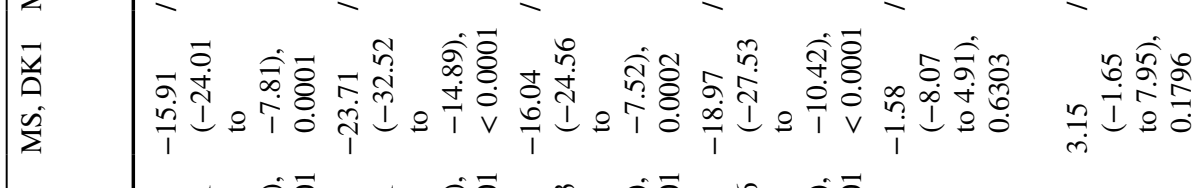

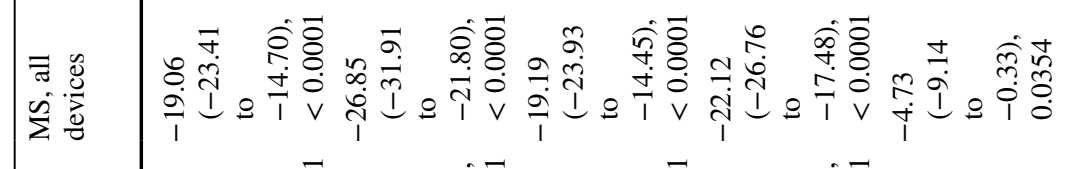

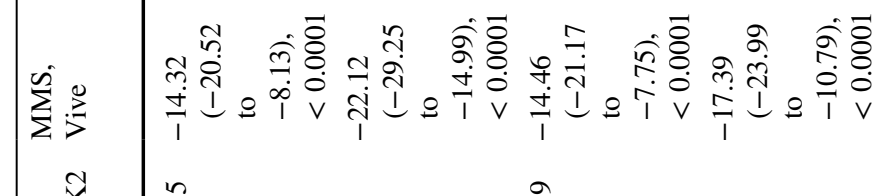

$$
\begin{aligned}
& \text { : }
\end{aligned}
$$




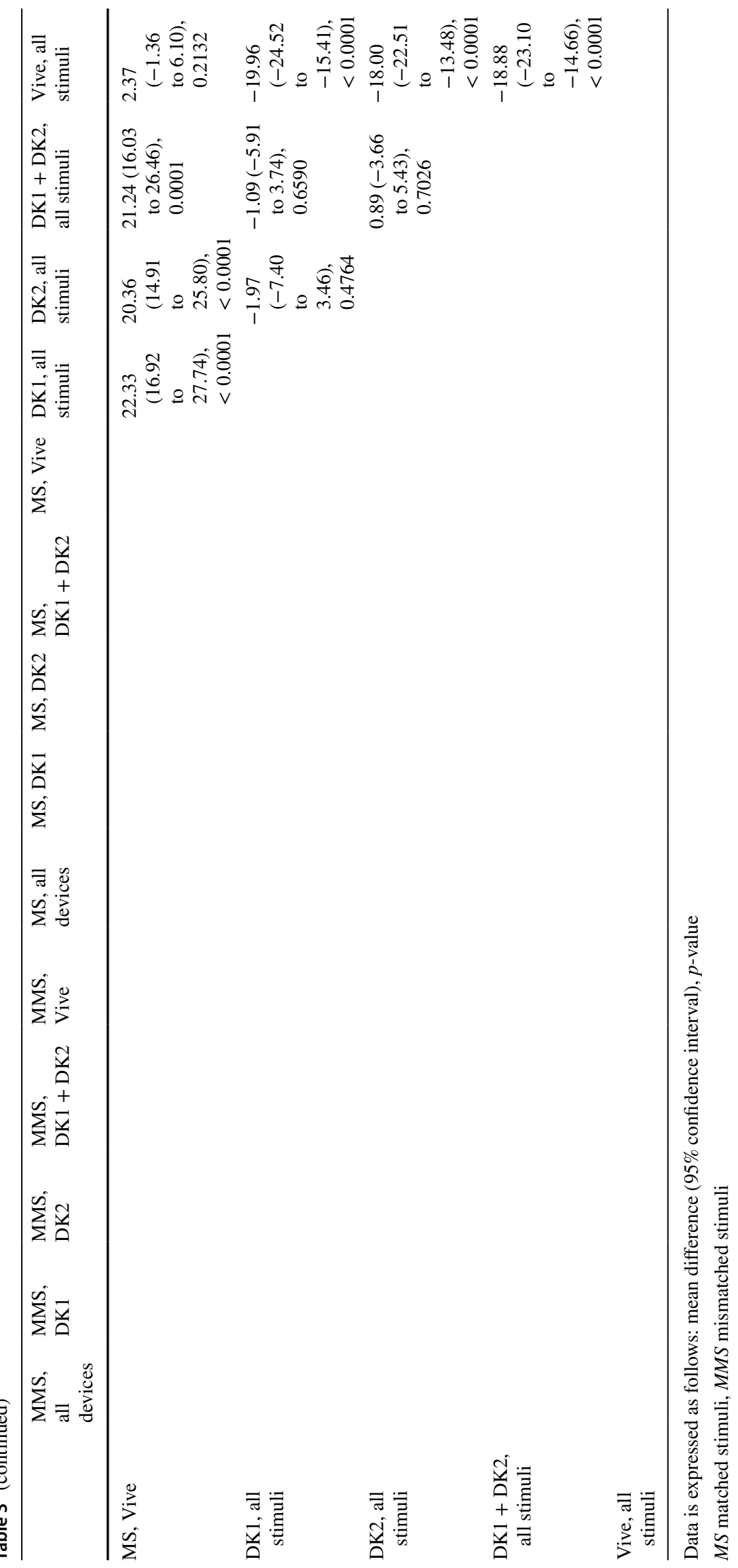


These results suggest that immersive VR applications such as virtual roller coasters (Nesbitt et al. 2017; Nalivaiko et al. 2015; Sra et al. 2019; Gavgani et al. 2017; Jin et al. 2018; Onuki et al. 2017), car simulations (Walch et al. 2017; Weidner et al. 2017; Rietzler et al. 2018; Oishi et al. 2016), bike driving simulators (Tran et al. 2018; Mittelstädt et al. 2019), flight simulations (Garcia-Agundez et al. 2019a; Mirhosseini et al. 2017) and wheelchair simulators (John et al. 2018; Chowdhury et al. 2017b) cause higher SSQ scores due to sensory mismatch and, in particular, due to perceived self-motion while remaining stationary. Some studies suggest that air cushions (Onuki et al. 2017) or vibrokinetic seats (Gardé et al. 2018) can mitigate CS symptoms while driving. Sra et al. (2019) furthermore found a similar result and reported that galvanic vestibular stimulation could also reduce $\mathrm{CS}$.

\subsubsection{Locomotion techniques}

Many studies investigated the effects of different locomotion techniques (see Table 4). The SSQ scores reported by Christou and Aristidou (2017) and Frommel et al. (2017) indicate that artificial continuous locomotion techniques are generally more likely to cause CS than discrete locomotion techniques. These results are also in agreement with Habgood et al. (2018). The authors did not provide explicit SSQ values; however, their results show that locomotion techniques with continuous movements, such as free joystick-based movements, cause significantly higher nausea and oculomotor scores than discrete movements, such as teleportation. Furthermore, Tregillus et al. (2017) compared different continuous locomotion techniques and according to Stanney et al. (1997) (pointing out that scores higher than 20 indicate a bad simulator), all three locomotion techniques seem to elicit CS.

Additional studies compared different artificial locomotion techniques with natural walking. In general, the results in Table 4 show low SSQ scores (on average, below 20) for natural walking. For example, Christensen et al. (2018) investigated two different conditions. The participants reported negligible symptoms when they could physically walk in the real world (SSQ scores of 1.87) and concerning symptoms when using a joystick (SSQ scores of 19.45). Similarly, the work of Llorach et al. (2014) shows that a position estimation system (SSQ scores of 15.93) induces less CS than game controllers (SSQ scores of 32.27). Furthermore, research by Wilson et al. (2018) suggests that natural walking without translation gain (one-to-one mapping of virtual space to physical space) causes only minimal CS symptoms (SSQ scores of 10.0). In contrast, additional translation gain causes significant CS symptoms (SSQ scores of 21.0). Moreover, Krekhov et al. (2018) pointed out that natural walking

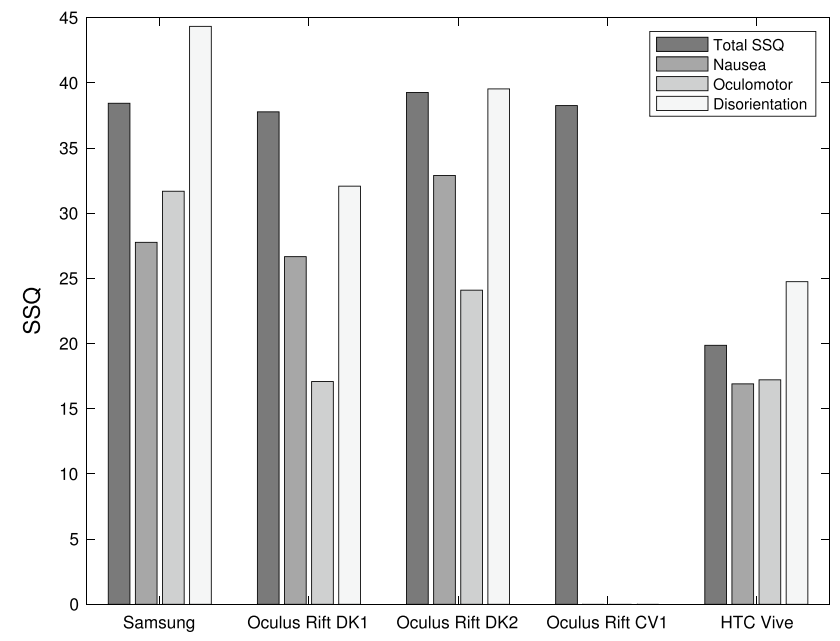

Fig. 2 SSQ score results classified by HMD

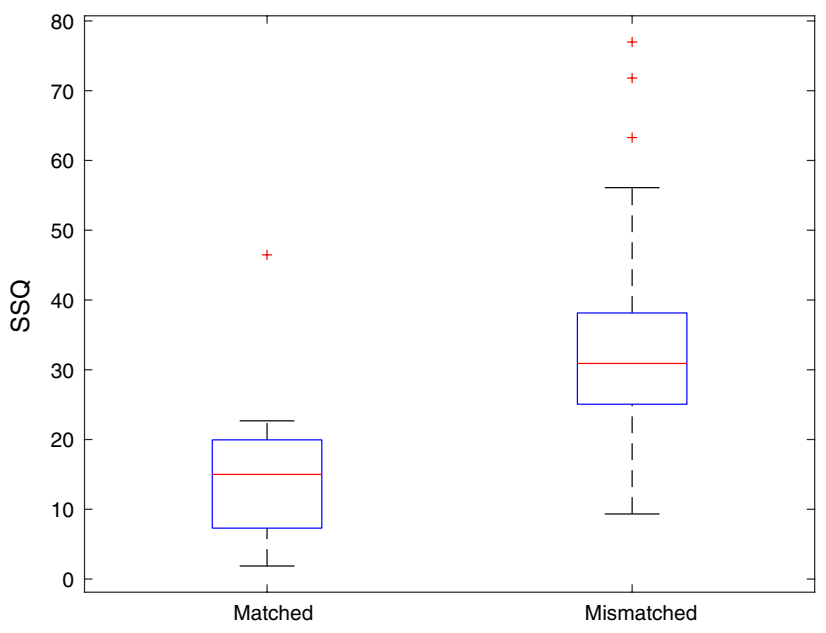

Fig. 3 SSQ scores classified by type of stimuli

as a giant causes lower SSQ scores (SSQ scores of 10.47) than teleportation (SSQ scores of 19.95).

\subsection{On biosignal-based alternatives to the SSQ}

As already stated in Sect. 1, the SSQ is a commonly used method to quantify CS. Another option to explore CS is to study its physiological effects. This effect can be measured via the analysis of different biosignals, as an alternative to subjective measures such as the SSQ. For example, CS has been reported to increase cortisol levels in saliva (Kennedy et al. 2010) or to cause tachycardia (Hu and Stern 1999; Imai et al. 2006). Furthermore, it seems that CS often correlates with facial pallor, sweating, and respiration rate variations (Johnson 2005) as well as with heart rate variability (Rieder et al. 2011). Unfortunately, individual differences in autonomic regulation and variations caused by the experience 
Table 4 Summary of studies investigating different locomotion techniques

\begin{tabular}{|c|c|c|}
\hline Article & Mismatched stimuli & Matched stimuli \\
\hline Christou and Aristidou (2017) & $\begin{array}{l}\text { Pointing }{ }^{\mathrm{a}}(36.4) \text { and gaze-directed } \\
\text { locomotion }^{\mathrm{a}}(25.4)\end{array}$ & Teleportation $^{\mathrm{b}}(17.5)$ \\
\hline Frommel et al. (2017) & $\begin{array}{l}\text { Guided locomotion } \\
\text { touchpad } \\
\text { a }^{\mathrm{a}}(38.34)\end{array}$ & Fixpoint teleportation $^{\mathrm{b}}$ (23.38) and free teleportation ${ }^{\mathrm{b}}$ (21.97) \\
\hline Tregillus et al. (2017) & $\begin{array}{l}\text { Tilt }^{\mathrm{a}}(28.28 \pm 30.8, \text { walking-in-place } \\
\text { combined with tilt }^{\mathrm{a}}(27.58 \pm 17.0) \\
\text { and joystick }{ }^{\mathrm{a}}(23.26 \pm 34.6)\end{array}$ & \\
\hline Christensen et al. (2018) & Joystick $^{\mathrm{a}}(19.45)$ & Natural walking $^{\mathrm{a}}(1.87)$ \\
\hline Llorach et al. (2014) & Joystick $^{\text {a }}(32.27 \pm 29.26)$ & Position estimation $^{\mathrm{a}}(15.93 \pm 14.81)$ \\
\hline Wilson et al. (2018) & $\begin{array}{l}\text { Natural walking with translation gain }{ }^{\mathrm{a}} \\
(21.0)\end{array}$ & Natural walking without translation gain ${ }^{\mathrm{a}}(10.0)$ \\
\hline Krekhov et al. (2018) & & $\begin{array}{l}\text { Natural walking as a giant }{ }^{\mathrm{a}}(10.47 \pm 10.21) \text { and teleportation } \\
(19.95 \pm 21.24)\end{array}$ \\
\hline
\end{tabular}

The numbers in brackets show average SSQ scores

a continuous

${ }^{\mathrm{b}}$ discrete locomotion technique

but not by a negative reaction to it (sickness) make it challenging to predict CS based on variables such as the heart rate or respiration rate (Kiryu and Iijima 2014).

Thus, in this section, we aim to determine how reliable biosignals are in detecting CS. The corpus was again filtered and all articles that did not use biosignals were excluded. A total of six articles fulfilled this criterion, which are presented in Table 5.

From these results, several observations can be drawn. Firstly, changes in galvanic skin response seem to be the most reliable method to detect CS. Four out of six studies used galvanic skin response to detect CS and also reported an increase or at least changes of statistical significance. Secondly, although CS clearly elicits changes in heart rate and heart rate variability, it does not seem that an increase or decrease can be explicitly linked to higher rates of CS. For example, an increase in heart rate can occur due to physical activity, whereas a decrease in heart rate variability can indicate a higher stress level. Thus, the heart rate does not seem to increase only due to CS. In this sense, heart rate alterations may be used to verify CS that has already been detected by a different method, such as galvanic skin response, changes of in-game behavior, or verbal communication.

Results also suggest that increases in the respiratory rate, basal finger temperature, or tachygastria may also be used to predict CS. In general, we believe these results confirm the advantage of biosignals to determine CS without using subjective questionnaires, such as SSQ.

\section{Discussion}

In this paper, we analyzed 49 studies that investigated CS among participants while they were immersed in a virtual environment using a current-generation HMD. We focused on determining whether there are differences in the CS patterns based on different HMDs, whether CS increases when stimuli do not match, and how biosignals can detect CS. A summary of the statistical conclusions based on the metaanalysis is provided in Table 6 .

Although more studies on the Oculus Rift CV1 are required, it is clear that last-generation HMD devices have significantly fewer problems with CS, although CS is still present. A comparison between different HMDs showed that HTC Vive with accurate positional tracking causes significantly less nausea and disorientation symptoms, but oculomotor ones remain at similar levels (see Sect. 3.1). More particularly, a meta-analysis revealed statistically significantly lower $(p<0.0001)$ SSQ scores for HTC Vive compared to Oculus Rift DK1 and DK2 (see also Table 6). Nevertheless, given the expansion of the VR market, numerous more studies are required to test all new HMDs reaching the market (Valve Index, Oculus Rift S, Oculus Quest, Samsung Odyssey, and Microsoft Augmented Reality devices).

Regarding the nature of movement, the meta-analysis revealed significant higher SSQ scores $(p<0.0001)$ for studies with mismatched stimuli compared to the studies with matched stimuli (see Sect. 3.2.1). In particular, VR simulations that force movements upon the users, e.g., virtual roller coasters, driving, and flying simulations, are more susceptible to CS (see Sect. 3.2.2). Additionally, the 
Table 5 Summary of studies using biosignals

\begin{tabular}{|c|c|c|c|c|c|c|}
\hline Article & $\begin{array}{l}\text { Dennison et al. } \\
\text { (2016) }\end{array}$ & $\begin{array}{l}\text { Nalivaiko et al. } \\
\text { (2015) }\end{array}$ & $\begin{array}{l}\text { Gavgani et al. } \\
\text { (2017) }\end{array}$ & $\begin{array}{l}\text { Garcia-Agundez } \\
\text { et al. }(2019 b)\end{array}$ & $\begin{array}{l}\text { Garcia-Agundez } \\
\text { et al. (2019a) }\end{array}$ & Gardé et al. (2018) \\
\hline \# of users & 20 & 26 & 14 & 13 & 66 & 45 \\
\hline VR time [min] & 10 & 14 & 15 & 15 & 9.5 & 10 \\
\hline HMD & Oculus Rift DK2 & Oculus Rift DK1 & Oculus Rift DK1 & Oculus Rift DK2 & Oculus Rift DK2 & Oculus Rift CV1 \\
\hline Epochs [s] & 120 & Not specified & 60 & Whole dataset & 30 & Whole dataset \\
\hline Heart rate & Increase ${ }^{* *}$ & Increase ${ }^{* *}$ & Increase ${ }^{* *}$ & Decrease & Decrease & \\
\hline Heart rate variability & Decrease* & & & Increase* & & Decrease* \\
\hline Gastric rhythm & Increase* & & & & Increase & \\
\hline Blink rate & Increase* & & & & Decrease & \\
\hline Respiratory rate & Increase ${ }^{* *}$ & & Increase* & & Decrease & \\
\hline Galvanic skin response & Increase & & Increase ${ }^{* *}$ & & Changes* & Increase ${ }^{* *}$ \\
\hline Basal finger temperature & & Changes & & & & \\
\hline ACC & $78 \%$ & & & & $82 \%$ & \\
\hline
\end{tabular}

ACC denotes maximum classifier accuracy in case the data was fed to a machine learning classifier algorithm. For this section, Dennison et al. (2016) refers to VR vs. non-VR (Monitor) classification, while Garcia-Agundez et al. (2019a) refers to CS vs. non-CS classification

*Statistic significance for $p<0.05$ and **statistical significance for $p<0.005$

results show that locomotion techniques (see Sect. 3.2.3) with mismatched stimuli (e.g., joystick-based locomotion techniques) cause significantly higher severity symptoms compared to locomotion techniques with matched stimuli (e.g., continuous movements such as natural walking or discrete movements such as teleportation). Especially joystickbased locomotion techniques that allow the user to sit on a stationary chair to explore the virtual environment through continuous movements significantly increase the probability that CS occurs. In contrast, natural walking results in lower SSQ scores, indicating that it does not provoke CS. This evidence complements related work (Rebenitsch and Owen 2016), showing that the navigation is still strongly correlated with CS. Recent research suggests that adding motion cues to the visual stimuli may not necessarily reduce CS (Klüver et al. 2015). Interestingly, there is evidence opposed to this conclusion in the case of simulators (Gardé et al. 2018).

Concerning biosignals, galvanic skin response is by far the best signal to predict and detect CS. More numerous studies exploring galvanic skin responses in users experiencing CS may provide sufficient information to develop a reliable linear regression algorithm to more accurately predict $\mathrm{CS}$ in real-time.

In summary, based on the meta-analysis, it appears that the nature of movement is the main reason for CS. To prevent that CS occurs in immersive VR applications and games, the developers should avoid sensory mismatch, i.e., they should provide room-scale environments where users can naturally walk in the physical and virtual world. If the direct mapping of movements in VR is limited by the physical tracking space, then the game should instead employ discrete locomotion techniques, such as teleportation. Modern
HMDs with accurate head tracking can also help to prevent CS.

In general terms, it seems the traditional evaluation scales for the SSQ, with scores over 20 describing "a bad simulator," are outdated. Significantly higher values can be expected across all HMDs and a new evaluation scale should be implemented. Considering that in our corpus a SSQ score of 40 or higher usually means a withdrawal rate of approximately one third, we suggest 40 would be a more precise value to describe "a bad simulator," meaning an outdated HMD or a VR scenario design that causes specifically abnormal levels of CS for current standards. This is not a critique on the SSQ itself, but more of an observation of differences of current VR and the simulators it was initially designed for.

Finally, we believe it is also important to restate some general remarks into how to conduct CS or SSQ-based studies in the future: samples should be larger than 15 users (Kennedy and Fowlkes 1992) and immersion times should be of at least $20 \mathrm{~min}$ (Wilson 1996). During the evaluation, early indicators of CS may be atypical eye movements, sweating, or fiddling with the HMD (Cobb et al. 1999). In general terms, the more correlated virtual and real movements are, the less CS than it is to be expected (LaViola 2000; Regan 1995a). Finally, SSQ values of up to 40 can be expected.

\subsection{Limitations}

We aimed to identify the main causes of CS; however, this article presents several limitations. Firstly, the number and nature of studies on the Oculus Rift CV1 are insufficient to 
Table 6 Summary of the meta-analysis

\begin{tabular}{|c|c|c|}
\hline Group & Result & Conclusion \\
\hline \multicolumn{3}{|l|}{ Different VR HMD } \\
\hline HTC Vive vs. Oculus Rift (DK1, DK2) & $p<0.0001$ & $\begin{array}{l}\text { Statistically significant (lower) SSQ scores for HTC Vive } \\
(13.98 \pm 19.08) \text { compared to Oculus Rift DK1 }(33.94 \pm 30.6) \\
\text { and DK2 }(31.97 \pm 31.41)\end{array}$ \\
\hline Oculus Rift DK1 vs. DK2 & $p=0.4764$ & $\begin{array}{l}\text { No statistical difference between both version of the Oculus } \\
\text { Rift }\end{array}$ \\
\hline \multicolumn{3}{|l|}{ Nature of movement } \\
\hline Matched vs. mismatched stimuli, independent of the HMD & $p<0.0001$ & $\begin{array}{l}\text { Statistically significant (higher) SSQ scores for mismatched } \\
(31.84 \pm 30.29) \text { compared to matched stimuli }(12.78 \pm 16.35)\end{array}$ \\
\hline Matched vs. mismatched stimuli for Oculus Rift DK1 & $p<0.0001$ & $\begin{array}{l}\text { Statistically significant (lower) SSQ scores for Oculus Rift } \\
\text { DK1 with matched }(15.93 \pm 14.81) \text { compared to mismatched } \\
\text { stimuli }(39.63 \pm 32.09)\end{array}$ \\
\hline Matched vs. mismatched stimuli for HTC Vive & $p=0.0169$ & $\begin{array}{l}\text { Statistically significant (lower) SSQ scores for HTC Vive with } \\
\text { matched }(11.61 \pm 16.78) \text { compared to mismatched stimuli } \\
(17.51 \pm 21.7)\end{array}$ \\
\hline
\end{tabular}

draw any significant conclusions on the impact of CS on this device. The same can be said for other HMDs released during 2019. In general terms, the number of studies on which we performed our meta-analysis was limited. Secondly, authors on VR-based CS studies tend not to provide full SSQ results or information on the dropout/CS complaint rates. However, despite these limitations, several conclusions based on statistically significant differences can be drawn from our meta-analysis.

\section{Conclusion}

In this paper, we have reviewed the state of the art research on CS with current-generation VR HMDs. We included 49 studies that met our criteria. To discuss the main causes of immersive VR-caused CS, we conducted a meta-analysis and compared different HMDs (e.g., Oculus Rift vs. HTC Vive) and stimuli (matched vs. mismatched). Firstly, the metaanalysis results show that last-generation HMD devices have significantly fewer problems with CS, although these are still present. Secondly, mismatched stimuli cause a significant increase in CS compared to matched stimuli. Especially VR flying or driving simulators as well as continuous locomotion techniques with mismatched stimuli (e.g., joystick-based movements), cause higher SSQ scores. In contrast, discrete locomotion techniques, such as teleportation or room-scale setups enabling natural walking cause significantly lower CS symptoms. Finally, concerning biosignals, galvanic skin response seems by far the best signal to predict and detect $\mathrm{CS}$ in real-time. We hope that this survey will encourage game developers and researchers in the future to study the causes and solutions regarding CS using modern HMDs.
Funding Open Access funding enabled and organized by Projekt DEAL.

\section{Declarations}

Conflict of interest The authors declare that they have no conflict of interest.

Open Access This article is licensed under a Creative Commons Attribution 4.0 International License, which permits use, sharing, adaptation, distribution and reproduction in any medium or format, as long as you give appropriate credit to the original author(s) and the source, provide a link to the Creative Commons licence, and indicate if changes were made. The images or other third party material in this article are included in the article's Creative Commons licence, unless indicated otherwise in a credit line to the material. If material is not included in the article's Creative Commons licence and your intended use is not permitted by statutory regulation or exceeds the permitted use, you will need to obtain permission directly from the copyright holder. To view a copy of this licence, visit http://creativecommons.org/licenses/by/4.0/.

\section{References}

Arcioni B, Palmisano S, Apthorp D, Kim J (2019) Postural stability predicts the likelihood of cybersickness in active HMD-based virtual reality. Displays 58:3-11. https://doi.org/10.1016/j.displa. 2018.07.001. Special issue: visually induced motion sensations

Arns LL, Cerney MM (2005) The relationship between age and incidence of cybersickness among immersive environment users. In: IEEE proceedings. VR 2005. Virtual reality (2005), pp 267-268. https://doi.org/10.1109/VR.2005.1492788

Bles W, Bos JE, de Graaf B, Groen E, Wertheim AH (1998) Motion sickness: only one provocative conflict? Brain Res Bull 47(5):481-487. https://doi.org/10.1016/S0361-9230(98)00115-4

Bos JE (2011) Nuancing the relationship between motion sickness and postural stability. Displays 32(4):189-193. https://doi.org/ 10.1016/j.displa.2010.09.005. Visual image safety 
Bos JE, Bles W, Groen EL (2008) A theory on visually induced motion sickness. Displays 29(2):47-57. https://doi.org/10.1016/j.displa. 2007.09.002. Health and safety aspects of visual displays

Bruck S, Watters PA (2011) The factor structure of cybersickness. Displays 32(4):153-158. https://doi.org/10.1016/j.displa.2011.07. 002. Visual image safety

Caserman P, Martinussen M, Göbel S (2019) Effects of end-to-end latency on user experience and performance in immersive virtual reality applications. In: van der Spek E, Göbel S, Do EYL, Clua E, Baalsrud Hauge J (eds) Entertainment computing and serious games. Lecture notes in computer science, vol 11863. Springer International Publishing, Cham, pp 57-69. https://doi.org/10. 1007/978-3-030-34644-7_5

Chang E, Kim HT, Yoo B (2020) Virtual reality sickness: a review of causes and measurements. Int J Hum Comput Interact 36(17):1658-1682. https://doi.org/10.1080/10447318.2020. 1778351

Chen Y, Zhang C, Zhang M, Fu X (2015) Three statistical experimental designs for enhancing yield of active compounds from herbal medicines and anti-motion sickness bioactivity. Pharmacogn Mag 11(43):435-443. https://doi.org/10.4103/0973-1296.160444

Chowdhury TI, Costa R, Quarles J (2017a) Information recall in a mobile VR disability simulation. In: 2017 9th International conference on virtual worlds and games for serious applications (VS-games), pp 125-128. https://doi.org/10.1109/VS-GAMES. 2017.8056580

Chowdhury TI, Ferdous SMS, Quarles J (2017b) Information recall in a virtual reality disability simulation. In: Proceedings of the 23rd ACM symposium on virtual reality software and technology, VRST '17. Association for Computing Machinery, New York. https://doi.org/10.1145/3139131.3139143

Christensen JV, Mathiesen M, Poulsen JH, Ustrup EE, Kraus M (2018) Player experience in a VR and non-VR multiplayer game. In: Proceedings of the virtual reality international conference-laval virtual, VRIC '18. Association for Computing Machinery, New York. https://doi.org/10.1145/3234253. 3234297

Christou CG, Aristidou P (2017) Steering versus teleport locomotion for head mounted displays. In: De Paolis LT, Bourdot P, Mongelli A (eds) Augmented reality, virtual reality, and computer graphics. Lecture notes in computer science, vol 10325. Springer International Publishing, Cham, pp 431-446. https://doi.org/10. 1007/978-3-319-60928-7_37

Cobb SVG, Nichols S, Ramsey A, Wilson JR (1999) Virtual realityinduced symptoms and effects (VRISE). Presence: Teleoperators Virtual Environ 8(2):169-186. https://doi.org/10.1162/10547 4699566152

Davis S, Nesbitt K, Nalivaiko E (2014) A systematic review of cybersickness. In: Proceedings of the 2014 conference on interactive entertainment, IE2014, pp 1-9. Association for Computing Machinery, New York. https://doi.org/10.1145/2677758.2677780

Deb S, Carruth DW, Sween R, Strawderman L, Garrison TM (2017) Efficacy of virtual reality in pedestrian safety research. Appl Ergon 65:449-460. https://doi.org/10.1016/j.apergo.2017.03.007

Dennison MS, D'Zmura M (2017) Cybersickness without the wobble: experimental results speak against postural instability theory. Appl Ergon 58:215-223. https://doi.org/10.1016/j.apergo.2016. 06.014

Dennison MS, Wisti AZ, D’Zmura M (2016) Use of physiological signals to predict cybersickness. Displays 44:42-52. https://doi.org/ 10.1016/j.displa.2016.07.002. Contains special issue articlesproceedings of the 4th symposium on liquid crystal photonics (SLCP 2015)
DiZio P, Lackner JR (1997) Circumventing side effects of immersive virtual environments. Adv Hum Factors/Ergon 21:893-896

DiZio P, Lackner JR (2000) Motion sickness side effects and aftereffects of immersive virtual environments created with helmetmounted visual displays. Technical report, Brandeis University, Waltham, MA, Ashton Graybiel Spatial Orientation Laboratory

Dorado JL, Figueroa PA (2014) Ramps are better than stairs to reduce cybersickness in applications based on a HMD and a gamepad. In: 2014 IEEE symposium on 3D user interfaces (3DUI), pp 47-50. https://doi.org/10.1109/3DUI.2014.6798841

Ebenholtz SM, Cohen MM, Linder BJ (1994) The possible role of nystagmus in motion sickness: a hypothesis. Aviat Space Environ Med 65(11):1032-1035

Farmani Y, Teather RJ (2018) Viewpoint snapping to reduce cybersickness in virtual reality. In: Proceedings of the 44th graphics interface conference, GI '18. Canadian Human-Computer Communications Society, Waterloo, pp 168-175. https://doi.org/10. 20380/GI2018.23

Frommel J, Sonntag S, Weber M (2017) Effects of controller-based locomotion on player experience in a virtual reality exploration game. In: Proceedings of the 12th international conference on the foundations of digital games, FDG ' 17 . Association for Computing Machinery, New York. https://doi.org/10.1145/3102071. 3102082

Fuchs P (2017) Virtual reality headsets-a theoretical and pragmatic approach. CRC Press, Boca Raton

Garcia-Agundez A, Reuter C, Becker H, Konrad R, Caserman P, Miede A, Göbel S (2019a) Development of a classifier to determine factors causing cybersickness in virtual reality environments. Games Health J 8(6):439-444. https://doi.org/10.1089/g4h.2019.0045

Garcia-Agundez A, Reuter C, Caserman P, Konrad R, Göbel S (2019b) Identifying cybersickness through heart rate variability alterations. Int J Virtual Real 19(1):1-10. https://doi.org/10.20870/ IJVR.2019.19.1.2907

Garcia-Agundez A, Westmeier A, Caserman P, Konrad R, Göbel S (2017) An evaluation of extrapolation and filtering techniques in head tracking for virtual environments to reduce cybersickness. In: Alcañiz M, Göbel S, Ma M, Fradinho Oliveira M, Baalsrud Hauge J, Marsh T (eds) Serious games. Lecture Notes in Computer Science, vol. 10622, pp 203-211. Springer International Publishing, Cham. https://doi.org/10.1007/978-3-319-70111-0 19

Gardé A, Léger PM, Sénécal S, Fredette M, Labonté-Lemoyne E, Courtemanche F, Ménard JF (2018) The effects of a vibro-kinetic multi-sensory experience in passive seated vehicular movement in a virtual reality context. In: Extended abstracts of the 2018 $\mathrm{CHI}$ conference on human factors in computing systems, CHI EA '18. Association for Computing Machinery, New York. https:// doi.org/10.1145/3170427.3188638

Gavgani AM, Nesbitt KV, Blackmore KL, Nalivaiko E (2017) Profiling subjective symptoms and autonomic changes associated with cybersickness. Auton Neurosci 203:41-50. https://doi.org/ 10.1016/j.autneu.2016.12.004

Golding JF (1998) Motion sickness susceptibility questionnaire revised and its relationship to other forms of sickness. Brain Res Bull 47(5):507-516. https://doi.org/10.1016/S0361-9230(98)00091-4

Golding JF, Gresty MA (2015) Pathophysiology and treatment of motion sickness. Curr Opin Neurol 28(1):83-88. https://doi.org/ 10.1097/WCO.0000000000000163

Habgood MPJ, Moore D, Wilson D, Alapont S (2018) Rapid, continuous movement between nodes as an accessible virtual reality locomotion technique. In: 2018 IEEE conference on virtual reality and 3D user interfaces (VR), pp 371-378. https://doi.org/10. 1109/VR.2018.8446130 
Hettinger LJ, Riccio GE (1992) Visually induced motion sickness in virtual environments. Presence: Teleoperators Virtual Environ 1(3):306-310. https://doi.org/10.1162/pres.1992.1.3.306

Howarth P, Costello P (1997) The occurrence of virtual simulation sickness symptoms when an HMD was used as a personal viewing system. Displays 18(2):107-116. https://doi.org/10.1016/ S0141-9382(97)00011-5

Hu S, Stern RM (1999) The retention of adaptation to motion sickness eliciting stimulation. Aviat Space Environ Med 70(8):766-768

Hunt X, Potter LE (2018) High computer gaming experience may cause higher virtual reality sickness. In: Proceedings of the 30th Australian conference on computer-human interaction, OzCHI '18. Association for Computing Machinery, New York, pp 598-601. https://doi.org/10.1145/3292147.3292225

Imai K, Kitakoji H, Sakita M (2006) Gastric arrhythmia and nausea of motion sickness induced in healthy Japanese subjects viewing an optokinetic rotating drum. J Physiol Sci 56(5):341-345. https:// doi.org/10.2170/physiolsci.RP005306

Iskenderova A, Weidner F, Broll W (2017) Drunk virtual reality gaming: exploring the influence of alcohol on cybersickness. In: Proceedings of the annual symposium on computer-human interaction in play, CHI PLAY '17, pp 561-572. https://doi.org/ $10.1145 / 3116595.3116618$

Jin W, Fan J, Gromala D, Pasquier P (2018) Automatic prediction of cybersickness for virtual reality games. In: 2018 IEEE games, entertainment, media conference (GEM), pp 1-9. https://doi.org/ 10.1109/GEM.2018.8516469

John NW, Pop SR, Day TW, Ritsos PD, Headleand CJ (2018) The implementation and validation of a virtual environment for training powered wheelchair manoeuvres. IEEE Trans Vis Comput Graph 24(5):1867-1878. https://doi.org/10.1109/TVCG.2017. 2700273

Johnson DM (2005) Introduction to and review of simulator sickness research. Technical report, Army Research Inst Field Unit Fort Rucker AL

Kennedy RS, Drexler J, Kennedy RC (2010) Research in visually induced motion sickness. Appl Ergon 41(4), 494-503. https:// doi.org/10.1016/j.apergo.2009.11.006. Special section-the first international symposium on visually induced motion sickness, fatigue, and photosensitive epileptic seizures (VIMS2007)

Kennedy RS, Fowlkes JE (1992) Simulator sickness is polygenic and polysymptomatic: implications for research. Int J Aviat Psychol 2(1):23-38. https://doi.org/10.1207/s15327108ijap0201_2

Kennedy RS, Lane NE, Berbaum KS, Lilienthal MG (1993) Simulator sickness questionnaire: an enhanced method for quantifying simulator sickness. Int J Aviat Psychol 3(3):203-220. https://doi. org/10.1207/s15327108ijap0303_3

Keshavarz B, Hecht H (2011) Validating an efficient method to quantify motion sickness. Hum Factors 53(4):415-426. https://doi. org/10.1177/0018720811403736

Keshavarz B, Riecke BE, Hettinger LJ, Campos JL (2015) Vection and visually induced motion sickness: how are they related? Front Psychol 6:472. https://doi.org/10.3389/fpsyg.2015.00472

Kim J, Chung CYL, Nakamura S, Palmisano S, Khuu SK (2015) The Oculus Rift: a cost-effective tool for studying visual-vestibular interactions in self-motion perception. Front Psychol 6:248. https://doi.org/10.3389/fpsyg.2015.00248

Kim YY, Kim HJ, Kim EN, Ko HD, Kim HT (2005) Characteristic changes in the physiological components of cybersickness. Psychophysiology 42(5):616-625. https://doi.org/10.1111/j. 1469-8986.2005.00349.x

Kiryu T, Iijima A (2014) A multi-timescale autonomic regulation model for interpreting visually induced motion sickness. In: 2014 IEEE 3rd global conference on consumer electronics (GCCE), pp 254-257. https://doi.org/10.1109/GCCE.2014. 7031258
Klüver M, Herrigel C, Preuß S, Schöner HP, Hecht H (2015) Comparing the incidence of simulator sickness in five different driving simulators. In: Proceedings of driving simulation conference

Kramida G (2016) Resolving the vergence-accommodation conflict in head-mounted displays. IEEE Trans Vis Comput Graph 22(7):1912-1931. https://doi.org/10.1109/TVCG.2015.2473855

Krekhov A, Cmentowski S, Emmerich K, Masuch M, Krüger J (2018) GulliVR: a walking-oriented technique for navigation in virtual reality games based on virtual body resizing. In: Proceedings of the 2018 annual symposium on computer-human interaction in play, CHI PLAY '18. Association for Computing Machinery, New York, pp 243-256. https://doi.org/10.1145/3242671.32427 04

James Smart LJ, Stoffregen TA, Bardy BG (2002) Visually induced motion sickness predicted by postural instability. Hum Factors 44(3):451-465. https://doi.org/10.1518/0018720024497745

Lampton DR, Kolasinski EM, Knerr BW, Bliss JP, Bailey JH, Witmer BG (1994) Side effects and aftereffects of immersion in virtual environments. In: Proceedings of the Human Factors and Ergonomics Society annual meeting, vol 38, no 18, pp 1154-1157. https://doi.org/10.1177/154193129403801802

LaViola JJ (2000) A discussion of cybersickness in virtual environments. SIGCHI Bull 32(1):47-56. https://doi.org/10.1145/ 333329.333344

Lee JY, Han PH, Tsai L, Peng RD, Chen YS, Chen KW, Hung YP (2017) Estimating the simulator sickness in immersive virtual reality with optical flow analysis. In: SIGGRAPH Asia 2017 posters, SA '17. Association for Computing Machinery, New York. https://doi.org/10.1145/3145690.3145697

Llorach G, Evans A, Blat J (2014) Simulator sickness and presence using HMDs: comparing use of a game controller and a position estimation system. In: Proceedings of the 20th ACM symposium on virtual reality software and technology, VRST '14. Association for Computing Machinery, New York, pp 137-140. https:// doi.org/10.1145/2671015.2671120

Lo W, So RH (2001) Cybersickness in the presence of scene rotational movements along different axes. Appl Ergon 32(1):1-14. https:// doi.org/10.1016/S0003-6870(00)00059-4

Lubeck AJ, Bos JE, Stins JF (2015) Motion in images is essential to cause motion sickness symptoms, but not to increase postural sway. Displays 38:55-61. https://doi.org/10.1016/j.displa.2015. 03.001

Luks R, Liarokapis F (2019) Investigating motion sickness techniques for immersive virtual environments. In: Proceedings of the 12th ACM international conference on PErvasive Technologies Related to Assistive environments, PETRA '19. Association for Computing Machinery, New York, pp 280-288. https://doi.org/ $10.1145 / 3316782.3321535$

Maloca PM, de Carvalho JER, Heeren T, Hasler PW, Mushtaq F, Mon-Williams M, Scholl HPN, Balaskas K, Egan C, Tufail A, Witthauer L, Cattin PC (2018) High-performance virtual reality volume rendering of original optical coherence tomography point-cloud data enhanced with real-time ray casting. Transl Vis Sci Technol 7(4):2. https://doi.org/10.1167/tvst.7.4.2

von Mammen S, Knote A, Edenhofer S (2016) Cyber sick but still having fun. In: Proceedings of the 22nd ACM conference on virtual reality software and technology, VRST '16. Association for Computing Machinery, New York, pp 325-326. https://doi. org/10.1145/2993369.2996349

McCauley ME, Sharkey TJ (1992) Cybersickness: perception of selfmotion in virtual environments. Presence: Teleoperators Virtual Environ 1(3):311-318. https://doi.org/10.1162/pres.1992.1.3.311

Merhi O, Faugloire E, Flanagan M, Stoffregen TA (2007) Motion sickness, console video games, and head-mounted displays. Hum Factors 49(5):920-934. https://doi.org/10.1518/001872007X 230262 
Mirhosseini S, Gutenko I, Ojal S, Marino J, Kaufman AE (2017) Automatic speed and direction control along constrained navigation paths. In: 2017 IEEE virtual reality (VR), pp 29-36. https://doi. org/10.1109/VR.2017.7892228

Mittelstädt JM, Wacker J, Stelling D (2019) Emotional and cognitive modulation of cybersickness: the role of pain catastrophizing and body awareness. Hum Factors 61(2):322-336. https://doi.org/10. 1177/0018720818804382

Moher D, Liberati A, Tetzlaff J, Altman DG (2009) The PRISMA Group: preferred reporting items for systematic reviews and meta-analyses: the PRISMA statement. Ann Intern Med 151(4):264-269. https://doi.org/10.7326/0003-4819-151-4200908180-00135

Mondellini M, Arlati S, Pizzagalli S, Greci L, Sacco M, Ferrigno G (2018) Assessment of the usability of an immersive virtual supermarket for the cognitive rehabilitation of elderly patients: a pilot study on young adults. In: 2018 IEEE 6th international conference on serious games and applications for health (SeGAH), pp 1-8. https://doi.org/10.1109/SeGAH.2018.8401313

Nalivaiko E, Davis SL, Blackmore KL, Vakulin A, Nesbitt KV (2015) Cybersickness provoked by head-mounted display affects cutaneous vascular tone, heart rate and reaction time. Physiol Behav 151:583-590. https://doi.org/10.1016/j.physbeh.2015.08.043

Nesbitt K, Davis S, Blackmore K, Nalivaiko E (2017) Correlating reaction time and nausea measures with traditional measures of cybersickness. Displays 48:1-8. https://doi.org/10.1016/j.displa. 2017.01.002

Nogalski M, Fohl W (2016) Acoustic redirected walking with auditory cues by means of wave field synthesis. In: 2016 IEEE virtual reality (VR). IEEE. pp 245-246. https://doi.org/10.1109/VR. 2016.7504745

Oishi E, Koge M, Khurelbaatar S, Kajimoto H (2016) Enhancement of motion sensation by pulling clothes. In: Proceedings of the 2016 symposium on spatial user interaction, SUI '16. Association for Computing Machinery, New York, pp 47-50. https://doi.org/10. $1145 / 2983310.2985749$

Onuki Y, Ono S, Kumazawa I (2017) Air cushion: a pilot study of the passive technique to mitigate simulator sickness by responding to vection. In: 2017 IEEE virtual reality (VR), pp 323-324. https:// doi.org/10.1109/VR.2017.7892307

Plouzeau J, Chardonnet JR, Merienne F (2018) Using cybersickness indicators to adapt navigation in virtual reality: a pre-study. In: 2018 IEEE conference on virtual reality and 3D user interfaces (VR), pp 661-662. https://doi.org/10.1109/VR.2018.8446192

Porter III J, Boyer M, Robb A (2018) Guidelines on successfully porting non-immersive games to virtual reality: a case study in minecraft. In: Proceedings of the 2018 annual symposium on computer-human interaction in play, CHI PLAY '18. Association for Computing Machinery, New York, pp 405-415. https:// doi.org/10.1145/3242671.3242677

Rangelova S, Motus D, André E (2020) Cybersickness among gamers: an online survey. In: Ahram T (ed) Advances in human factors in wearable technologies and game design. Springer International Publishing, Cham, pp 192-201. https://doi.org/10.1007/978-3030-20476-1_20

Reason JT, Brand JJ (1975) Motion sickness. Academic Press, New York

Rebenitsch L, Owen C (2016) Review on cybersickness in applications and visual displays. Virtual Real 20(2):101-125. https://doi.org/ 10.1007/s10055-016-0285-9

Regan C (1995a) An investigation into nausea and other side-effects of head-coupled immersive virtual reality. Virtual Reality 1(1):1731. https://doi.org/10.1007/BF02009710

Regan E (1995b) Some evidence of adaptation to immersion in virtual reality. Displays 16(3):135-139. https://doi.org/10.1016/01419382(96)81213-3
Reis L, Duarte E, Rebelo F (2015) Research on workplace safety sign compliance: validation of a virtual environment prototype. Procedia Manuf 3:6599-6606. https://doi.org/10.1016/j.promfg. 2015.07.722

Riccio GE, Stoffregen TA (1991) An ecological theory of motion sickness and postural instability. Ecol Psychol 3(3):195-240. https:// doi.org/10.1207/s15326969eco0303_2

Rieder R, Kristensen CH, Pinho MS (2011) Identifying relationships between physiological measures and evaluation metrics for 3D interaction techniques. In: Campos P, Graham N, Jorge J, Nunes N, Palanque P, Winckler M (eds) Human-computer interactionINTERACT 2011. Springer, Berlin, pp 662-679. https://doi.org/ 10.1007/978-3-642-23765-2_45

Rietzler M, Hirzle T, Gugenheimer J, Frommel J, Dreja T, Rukzio E (2018) VRSpinning: exploring the design space of a 1D rotation platform to increase the perception of self-motion in VR. In: Proceedings of the 2018 designing interactive systems conference, DIS '18. Association for Computing Machinery, New York, pp 99-108. https://doi.org/10.1145/3196709.3196755

Roberts WK, Gallimore JJ (2005) A physiological model of cybersickness during virtual environment interaction. In: Proceedings of the Human Factors and Ergonomics Society annual meeting, vol 49, no 26, pp 2230-2234. https://doi.org/10.1177/1541931205 04902603

Ryge AN, Vollmers C, Hvass JS, Andersen LK, Berthelsen T, BruunPedersen JR, Nilsson NC, Nordahl R (2018) A preliminary investigation of the effects of discrete virtual rotation on cybersickness. In: 2018 IEEE conference on virtual reality and 3D user interfaces (VR), pp 675-676. https://doi.org/10.1109/VR.2018. 8446206

Sargunam SP, Ragan ED (2018) Evaluating joystick control for view rotation in virtual reality with continuous turning, discrete turning, and field-of-view reduction. In: Proceedings of the 3rd international workshop on interactive and spatial computing, IWISC '18. Association for Computing Machinery, New York, pp 74-79. https://doi.org/10.1145/3191801.3191815

Sawada Y, Itaguchi Y, Hayashi M, Aigo K, Miyagi T, Miki M, Kimura T, Miyazaki M (2020) Effects of synchronised engine sound and vibration presentation on visually induced motion sickness. Sci Rep 10(1):1-10. https://doi.org/10.1038/s41598-020-64302-y

Schwarzer G, Carpenter JR, Rücker G (2015) Meta-analysis with R, vol 4784. Springer, Berlin

So RHY, Lo WT (1999) Cybersickness: an experimental study to isolate the effects of rotational scene oscillations. In: Proceedings IEEE virtual reality (Cat. No. 99CB36316), pp 237-241. https:// doi.org/10.1109/VR.1999.756957

Sra M, Jain A, Maes P (2019) Adding proprioceptive feedback to virtual reality experiences using galvanic vestibular stimulation. In: Proceedings of the $2019 \mathrm{CHI}$ conference on human factors in computing systems, CHI '19. Association for Computing Machinery, New York. https://doi.org/10.1145/3290605.3300905

Stanney KM, Hale KS, Nahmens I, Kennedy RS (2003) What to expect from immersive virtual environment exposure: influences of gender, body mass index, and past experience. Hum Factors 45(3):504-520. https://doi.org/10.1518/hfes.45.3.504. 27254

Stanney KM, Kennedy RS, Drexler JM (1997) Cybersickness is not simulator sickness. In: Proceedings of the Human Factors and Ergonomics Society annual meeting, vol 41, no 2, pp 1138-1142. https://doi.org/10.1177/107118139704100292

Stauffert JP, Niebling F, Latoschik ME (2018) Effects of latency jitter on simulator sickness in a search task. In: 2018 IEEE conference on virtual reality and 3D user interfaces (VR), pp 121-127. https://doi.org/10.1109/VR.2018.8446195

Steinicke F, Bruder G (2014) A self-experimentation report about longterm use of fully-immersive technology. In: Proceedings of the 
2nd ACM symposium on spatial user interaction, SUI '14. Association for Computing Machinery, New York, pp 66-69. https:// doi.org/10.1145/2659766.2659767

Tran TQ, Tran TDN, Nguyen TD, Regenbrecht H, Tran MT (2018) Can we perceive changes in our moving speed: a comparison between directly and indirectly powering the locomotion in virtual environments. In: Proceedings of the 24th ACM symposium on virtual reality software and technology, VRST'18. Association for Computing Machinery, New York. https://doi.org/10. $1145 / 3281505.3281510$

Tregillus S, Al Zayer M, Folmer E (2017) Handsfree omnidirectional VR navigation using head tilt. In: Proceedings of the $2017 \mathrm{CHI}$ conference on human factors in computing systems, CHI ' 17 . Association for Computing Machinery, New York, pp 40634068. https://doi.org/10.1145/3025453.3025521

Treisman M (1977) Motion sickness: an evolutionary hypothesis. Science 197(4302):493-495. https://doi.org/10.1126/science. 301659

Viirre E, Ellisman M (2003) Vertigo in virtual reality with haptics: case report. CyberPsychol Behav 6(4):429-431. https://doi.org/ $10.1089 / 109493103322278826$

Walch M, Frommel J, Rogers K, Schüssel F, Hock P, Dobbelstein D, Weber M (2017) Evaluating VR driving simulation from a player experience perspective. In: Proceedings of the 2017 CHI conference extended abstracts on human factors in computing systems, CHI EA '17. Association for Computing Machinery, New York, pp 2982-2989. https://doi.org/10.1145/3027063.3053202

Weidner F, Hoesch A, Poeschl S, Broll W (2017) Comparing VR and non-VR driving simulations: an experimental user study. In: 2017 IEEE virtual reality (VR), pp 281-282. https://doi.org/10.1109/ VR.2017.7892286

Whittinghill DM, Ziegler B, Case T, Moore B (2015) Nasum virtualis: a simple technique for reducing simulator sickness. In: Games developers conference (GDC), p 74
Wienrich C, Weidner CK, Schatto C, Obremski D, Israel JH (2018) A virtual nose as a rest-frame-the impact on simulator sickness and game experience. In: 2018 10th International conference on virtual worlds and games for serious applications (VS-games), pp 1-8. https://doi.org/10.1109/VS-Games.2018.8493408

Wilson G, McGill M, Jamieson M, Williamson JR, Brewster SA (2018) Object manipulation in virtual reality under increasing levels of translational gain. In: Proceedings of the $2018 \mathrm{CHI}$ conference on human factors in computing systems, CHI '18. Association for Computing Machinery, New York. https://doi.org/10.1145/ 3173574.3173673

Wilson JR (1996) Effects of participating in virtual environmentsa review of current knowledge. Saf Sci 23(1):39-51. https://doi. org/10.1016/0925-7535(96)00026-4

Yu X, Weng D, Cai L (2016) Reduce simulator sickness by overwritten symbol in smartphone-based VR system. In: 2016 International conference on virtual reality and visualization (ICVRV), pp 426-429. https://doi.org/10.1109/ICVRV.2016.78

Ziegler P, Roth D, Knots A, Kreuzer M, von Mammen S (2018) Simulator sick but still immersed: a comparison of head-object collision handling and their impact on fun, immersion, and simulator sickness. In: 2018 IEEE conference on virtual reality and 3D user interfaces (VR), pp 743-744. https://doi.org/10.1109/VR. 2018.8446221

Publisher's Note Springer Nature remains neutral with regard to jurisdictional claims in published maps and institutional affiliations. 